\title{
Vowel Epenthesis in Loanword Integration: A Study of English Consonant Cluster at Onset
}

\author{
Muhammad Asad Habib ${ }^{1} \&$ Arshad Ali Khan ${ }^{2}$ \\ ${ }^{1}$ Department of English Language and Literature, University of Management and Technology, Lahore, Pakistan \\ ${ }^{2}$ Institute of Communication and Cultural Studies, University of Management and Technology, Lahore, Pakistan \\ Correspondence: Muhammad Asad Habib, Department of English Language and Literature, University of \\ Management and Technology, Lahore, Pakistan. E-mail: masadlhr29@gmail.com
}

Received: May 10, 2019 Accepted: June 4, 2019 Online Published: July 12, 2019

doi:10.5539/ijel.v9n4p332 URL: https://doi.org/10.5539/ijel.v9n4p332

\begin{abstract}
This study examines the process of vowel epenthesis used by the Punjabi speakers to integrate the English consonant cluster at onset position of the syllable. English and Punjabi are two different phonological system where English allows consonant cluster and complex consonants at onset while Punjabi only allows complex consonants. Hence for the integration of syllables with consonant cluster, Punjabi speakers have to insert a vowel to make the consonant configuration according to Punjabi phonotactics. The data for this study are collected from recordings of focus group discussions, interviews and video clips. The data are analyzed by using CV phonology and Distinct Feature theory. The results suggest that Punjabi speakers insert vowels to modify the English consonant clusters according to Punjabi phonological environment. Thus, they add another vowel node and resyllabify the consonant clusters. The mid central/a/ vowel is the default epenthetic vowel while in some cases /e/ is also used before the consonant clusters.
\end{abstract}

Keywords: epenthesis, anaptyxis, prothesis, resyllabify, declusterize, phonotactics

\section{Introduction}

This study examines the use of vowel epenthesis by the Punjabi speakers into the unrecognized consonant clusters of English words at the onset position. The study also inspects the resyllabification process used by the Punjabi speakers in order to declusterize the English syllables. The analysis of the data enfolds that the Punjabi speakers change the syllable structure of the English words and use the epenthesis of vowel as a modification strategy. This epenthesis of the vowel before and in the consonant cluster is due to the influence of Punjabi syllable typology. Hence, the mother tongue influence is also evident.

The contact between English and Punjabi language necessitates the borrowing of words from one language to another. In this regard, English language due to its colonial past and being the official language of both Pakistan and India has a major share in this exchange. Punjabi language has taken a lot of words from English and integrated it in to Punjabi lexicon. The integration of these words is done at phonological, morphological, syntactic and orthographical levels. On the phonological level, one of the common strategies used by Punjabi speakers is the epenthesis of vowel in consonant clusters.

Among all the languages spoken in Pakistan, Punjabi is spoken and understood by majority of the people. Punjabi language is graded among the top twenty most spoken languages of the world (Comrie, Matthews, \& Polinsky, 1996). Punjabi is an international language and its speakers are found in almost all parts of the world. It is extensively spoken in India and Pakistan. In Pakistan more than 54\% population speak Punjabi as their native language. There are 92,721,700 speakers, majority of which lives in area of province Punjab (Baart \& Baart-Bremer, 2001), however, in India, 29,258,970 people use Punjabi as their first language. The scripts used by speakers of Punjabi in India and Pakistan are different. In Indian side of Punjab, the script used by the Punjabi speakers is called Gurmukhi while in Pakistani Punjab Shahmukhi is used.

Although, Punjabi is spoken widely yet it lacks prestige and status in Pakistan. Punjabi is not the medium of instruction and it is not taught or encouraged. The situation in Indian side of Punjab is different where Punjabi is given the status of one of the official languages by the state. Punjabi is taught and encouraged. In Pakistani side, 
the status and prestige are lying with English and Urdu. Urdu is National language and English enjoys the status of official language (Rahman, 1999).

There are many different dialects of the Punjabi language that are spoken in both Pakistan and India. The work done by different researchers on Punjabi language classified numerous dialects in Punjabi language. Rahman (2002) argues that one of the reason due to which the Punjabi cannot attain politically strong status is the greater number of dialects than any other language in Pakistan. Majhi, Puadhi, Doabi, Malvai and Puadhi are considered to be the main dialects of Punjabi (Bhatia, 2000). This study focuses on the Punjabi spoken in Lahore where Majhi dialect is spoken by the native Lahori tenants.

English and Punjabi are two different languages and have two different phonological systems which Bloomfield (1933) refers as unique values. Therefore, the English words spoken by the Punjabi speakers are restructured according to the Punjabi phonological structures. This restructuring of the words is done by resyllabifying the English word in conformity to Punjabi syllable typology. Syllabification is the arrangement of the CV in words (Crystal, 1997). Resyllabification is the rearrangement of the CV elements of syllable according to the phonological environment of other language. This involve the change in the syllable sequence of English like CCVVC into more discernable CVCVC structure in Punjabi.

Resyllabification is procedure of restructuring the syllable tiers from the donor language to the pattern recognizable in the phonology of receiving language. In this study, resyllabification will be studied from the prospect of English as a donor language and Punjabi as the receiving language. English recognize syllable with consonant cluster both at onset and coda positions while Punjabi does not recognize consonant clusters at both onset and coda. It entails that for the integration of English loan words in Punjabi, English loan words has to be resyllabified in order to suite Punjabi syllable typology. It implies the handling of consonant clusters (CCVC) or (CCCVC) not present in Punjabi Phonology.

This entails that the English words entering into Punjabi phonological system are changed. In this respect, the current study investigates phonological changes occurring to sequence of sounds which are either different form the Punjabi sound or do not exist in Punjabi at all. This analysis is based on the examination of unique syllable typology of English words that are restructured according to syllable structure of Punjabi. This restructuring involves the changes made to the syllable structure. Syllable is defined as a complex whole consisting of nuclears and the marginal elements (Laver, 1994). Nuclears consist of vowel and the marginal elements consist of consonants. The presence of nuclears is mandatory but the marginal elements are optional. Marginal elements exist either before the nuclears or after the nuclears or on the both sides of nuclears. Punjabi speakers make changes in both nuclears and marginal elements. Hence, the study is an exploration into the arrangements of nuclears and the marginal elements.

The study is based on the auditory judgments made by the Punjabi speakers of English. The data for this study is taken from the Punjabi speakers living in Lahore region. For the collection of data, researcher has used three different techniques which includes focus group discussions, structured and unstructured interviews and recordings of clips taken from Punjabi talk shows. For the analysis and presentation of the data, two different yet inter related Generative theories are used: CV phonology and Distinctive feature theory.

\subsection{Research Questions}

1) What are possible patterns of insertion of vowel in English words at onset by Punjabi learners.

\section{Literature Review}

In this globalized world, languages have come in closer contact than ever before. This unprecedented contact between the languages have led to structural changes in languages. These structural changes have caused the languages to excel and in the process of their development they show the tendency to accept the elements of another language or to effect other languages while they are in contact. Jakobson (1971) asserts that a language can receive elements from the foreign language only when it corresponds to its own propensities of development. During this development, words may be added or lost: while new vocabulary is accepted into a language, some words may fall into disuse and become obsolete. This happens mainly due to two factors. One of the factors is analogic change or the internal change. The analogic change happens due to the similarity between one word of the language to another word in the same language (Hock, 2003). The other factor responsible for language change is the effect of language contact. The changes, therefore, occurring are referred to as contact induced changes. There is every possibility that these two factors work simultaneously, resulting in change in the language. So, these changes, as suggested by (Thomason \& Kaufman, 2001), are the outcome of multiple causation. 
The contact among languages cause different kind of changes in the structure of languages involved. As Fromkin and Rodman (1998 p, 459) noted: "Changes in the lexicon also occur, including the addition of new words, changes in the meanings of words, and loss of words." Words may enter a language in many ways. Fromkin and Rodman (1998) mention compounding, derivational processes, coinage, recombining old words to form new ones with new meanings, and borrowing. Many modern-day scholars would approve that change in grammar or lexicon is the result of language contact. Nevertheless, opposing views in this regard has also been seen. Earlier linguist like Muller (1871) refused the possibility of interference in the grammar of the contact induced languages. Poplack and Levey (2010) supports this view. On the other hand, Schuchardt (1928) denies the idea and claims that influence of one morphological system on another is unlimited (as cited in Weinreich, 1953).

The nature of language contact can be small or great in magnitude and these changes are usually focused in one direction. When a language has a clear dominance in different social domains, it exerts greater influence on the recessive than the recessive does on the dominant language (Thomason, 2003). As people and communities interact with each other, this dynamic relationship may induce different possible consequences. The dominant (superordinate) language may adopt the role of lexical donor, resulting in providing certain kinds of words or morphemes for the adaptation by the speakers of the recessive (subordinate) language. On the other hand, the subordinate language becomes the receiver of the donated words. This receiving language provides a matrix for the elements to be embedded (Thomason, 2003). In this contact two things are likely to happen: (1) speakers from both languages will exchange some useful phrases. (2) Speakers from one group will borrow some words from the other group's language for those things that are not found in the linguistic repertoire of the first group (Myers-Scotton, 2005). In some unusual circumstances, borrowed words replace native ones to such a degree that a new and distinct variety emerges (Thomason \& Kaufman, 2008).

Among different languages lexical influence exerted by powerful language on lesser powerful languages is a common happening, but it is important to note that a receiver language shows the loan phonological and morphological features. The same can be seen in Punjabi as well, but on linguistic aspects almost nothing has been studied. The contact situation between Punjabi and English, in Pakistan, aids transmission of lexical items from English to Punjabi and vice versa. English, being one of the most dominant languages of the world English has taken the role of the most influential donor of lexical items to other languages (Zivenge, 2009). The fact that English is the medium of instruction, in Pakistan, language of technology, education, media, new administration, health, music, new religion and economic transactions means that it is regarded as the high variety language with coercive loaning powers. Words from English are then adopted in the Punjabi language.

According to Rodgers (1995) the words taken from foreign languages are always shaped in a different linguistic environment. The words are restructured phonologically and morphologically according to the phonological and morphological structure of recipient language. This shows that while the English loan words have their own phonological and morphological structures, the integration process like substitution, epenthesis and affixation etc. are used by the Punjabi speakers to make the word linguistically acceptable in Punjabi phonology and morphology. Study of both phonological and morphological process requires more time and thus, is beyond the scope of this study. Therefore, this study tries to explain the phonological behavior and modifications in English words used by Punjabi speakers and is limited to the modification made by Punjabi speakers in the consonant clusters at onset.

The loan words adopt the consonant vowel association patterns in their native language which is governed by English CV tiers allowed in English phonology. Thus, the changes to integrated loan words are made according to CV tier acceptable in Punjabi to suit the Punjabi phonological environment. Punjabi syllable structure allows a single onset consonant while English syllable allows up to three consonants. This possess a difficulty to Punjabi speakers. Therefore, Punjabi speaker has to modify the configuration of the onset of the loan words according to their own CV rules.

The aim of the study is to describe the process of vowel epenthesis in onset consonant clusters of the English loan words. The analysis of phonological process thus entails how the Punjabi speakers manage aspects of English language which are unrecognizable in their environment. The study also explains the notion that modifications made by the Punjabi speakers in the onset cluster are rule governed and thus, the study endeavors to explain the rules for the epenthesis of vowel in to English loan words.

\section{Methodology}

This study is based on English words spoken by Punjabi speakers. For this purpose, Generative phonology is taken as a theoretical frame work. Further, in Generative phonology CV phonology and distinctive feature theory 
is taken for the Data analysis. The main reason for opting this frame work is that it is not only the guide to the data analysis and data presentation but it also provides the underlaying process of phonological changes.

CV theory was proposed by Clements and Keyser (1983) and its major concern is to provide explanation for the syllable structure. As advocated by Clement and Keyser (1983) the major purpose of CV phonology is to determine and explain syllable structure. Syllable is taken as hierarchical unit with tiers called immediate constituents. According to Clements and Keyser, syllable constitutes of three tiers i.e., the syllable node, the CV-tier and the tier for the bundles to distinguish the parts (1983). The first tier (CV tier) will define the syllable patterns and the distinctive feature of the words. The $\mathrm{CV}$-tier, explains the syllabicity of the onset and bordering elements; hence it gives insightful picture of the complications of distinctive features and syllable patterns of lexemes. These tiers are shown by the English word/bin/ in Figure 1.

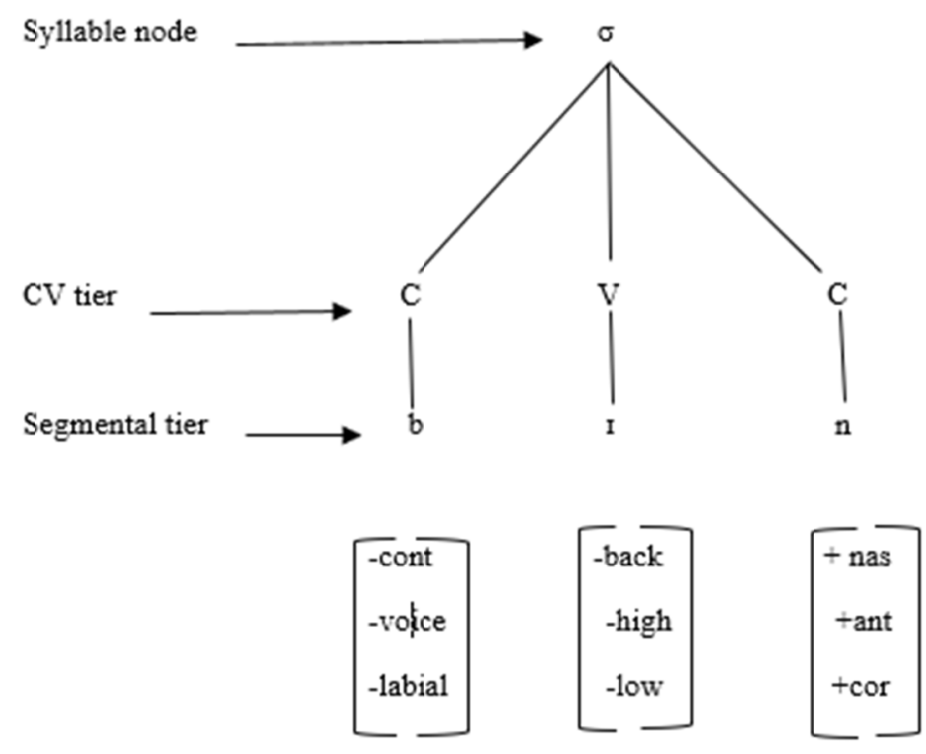

Figure 1. The syllable showing three tiers

The above given model clearly indicates that syllable tier dominants the CV-tier and the CV-tier dominates the segmental tier. $\mathrm{C}$ and $\mathrm{V}$ in the $\mathrm{CV}$-tier define functional positions: differentiates between the syllable peak and the non-peaks. In CV-tier the V element indicates the syllable peak (nucleus) which is also the peak of sonority. The nodes are linked to segments by association lines. Furthermore, a single $\sigma$ node dominates every maximal sequence of segments which constitute a syllable.

CV Phonology also gives the explanation of phonological changes taking place between English and Punjabi by considering the prominence factor and applying the combination of the segments. It will also inspect the consonant vowel (CV) arrangement and its patterns, syllable structure and its typology. An important aspect of this study is the syllable behavior of the two languages for which this theory is found suitable, therefore, the presentation of empirical data will be easy by using consonant-vowel (CV) notation. This notation shows the inputs and outputs in structural ways making it easy to understand the different patterns of consonant-vowel combinations.

This work is concentrated on resyllabification of English words spoken by Punjabi speakers at phonemic and syllable level, therefore, distinctive feature and CV phonology models are taken as the theoretical frame work for this study.

\subsection{Data Collection}

This work is descriptive in nature and will adopt a mix method approach for collection and analyzing data. This approach is useful for research concerning languages as it is more humanistic and cannot be studied in control environment. The target population of this study is the Punjabi speech community residing in district Lahore. The Sample consists of recordings of focus group discussions, interviews and video clips consisting of Punjabi 
talk shows. Purposive sampling technique is used for the selection of sample. Four native speakers of Punjabi are selected. They are all native Punjabi speakers. These four authenticated the data as samples for its analysis.

\section{Data Analysis}

Dealing with consonant cluster of English language requires modification into the consonant configurations. There are different ways to modify the consonant clusters which include the addition and deletion of consonants and vowels. It also comprises of replacement of the sound which are present in English but not present in Punjabi phonemic inventory. Furthermore, epenthesis of vowels is also used by the Punjabi speakers as a modification strategy. This study is limited to the epenthesis of vowels thus, the discussion is limited to the process of vowel epenthesis in the consonants cluster and before the consonants cluster.

Punjabi speakers insert vowels to modify and integrate the English consonant clusters. Insertion of vowels into the consonants is called vowel epenthesis (Hall, 2011). The epenthesis of vowel is done by the Punjabi speakers as a strategy to modify the syllable structure of English loan words according to Punjabi syllable structure. English words are different from Punjabi syllable structures because English possess consonant clusters both at onset and coda (Ladefoged \& Johnson, 2014) while Punjabi does not have consonant clusters instead Punjabi possesses complex consonants. The difference between consonant cluster and complex consonant is that in consonant clusters, consonants are arranged in CC pattern and are not articulated simultaneously (Kadenge, 2003), while in complex consonants the consonants follow the CC pattern but articulated simultaneously. Thus, these complex consonants are coarticulated as unitary gesture (Zivenge, 2009). The complex consonants can be double and triple yet they are regarded as one complex consonant and they are not considered as consonant clusters and are given unitary treatment. It entails that the English word having CC clusters should either be coarticulated in Punjabi phonology or the cluster will be broken by inserting a vowel between the CC cluster to make it a CVC structure. The example of CC cluster coarticulated can be seen in the word /pla:nt/ 'plant'. The Punjabi speaker will pronounce it as /pəla:nt/ maintaining the complex consonant at the end while changing the onset consonant cluster by inserting a vowel. The example of complex consonant $/ \mathrm{nt} /$ and the epenthesis of vowel is given in the Figures 2 and 3 respectively.

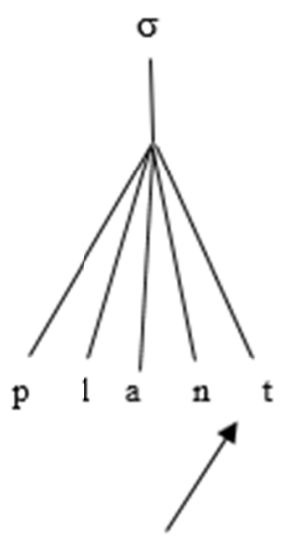

Figure 2. Complex consonant /nt/ in the word /pla:nt/

[Input] / pla:nt / vowel insertion $/ \mathfrak{x} \longrightarrow$ / pla:nt/ [output] 

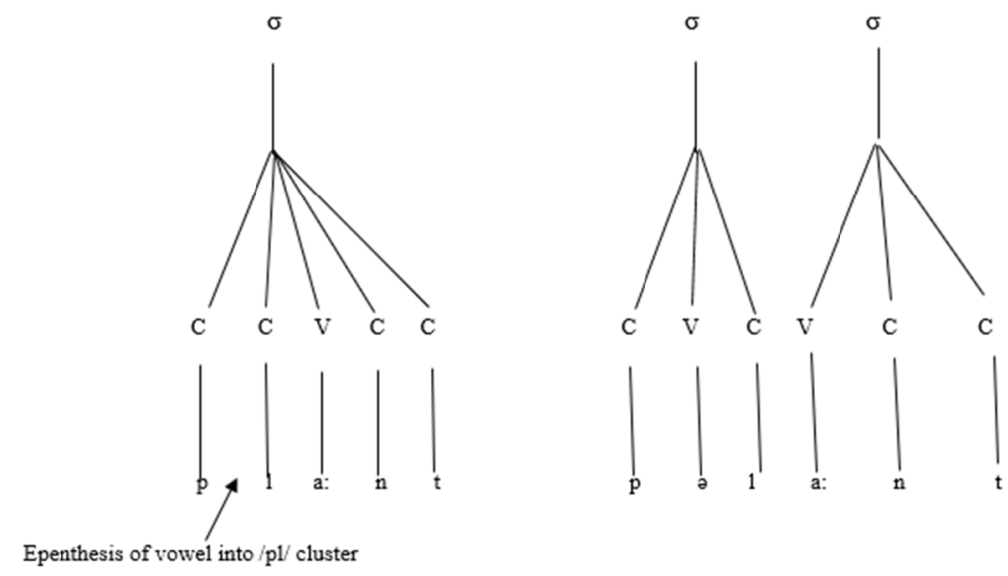

Figure 3. Epenthesis of vowel into /pl/ cluster

Punjabi contains complex consonants at the coda position of the syllable. The onset in the Punjabi syllable generally, does not possess either complex consonant or consonant cluster. This puts a constraint on the Punjabi language. In order to borrow any word from a language which possesses consonant cluster, Punjabi has to modify it by placing a vowel in between the consonant or changing the nature of the consonants. This is a phonotactic constraint in Punjabi language that do not allow any consonant cluster in Punjabi phonology.

English language recognizes consonant clusters in both onset and coda positions. Hence, the phonological structure of English syllables does not accord to Punjabi syllable structure. There are two positions in the syllable where the process of vowel epenthesis can occur: syllable initial (onset) or syllable final (coda). This study only deals with the cluster present on the onset of the vowel.

\subsection{Vowel Epenthesis at Onset}

As mentioned above, Punjabi does not have a consonant cluster at the onset position in a syllable. On the contrary, English possesses consonant clusters at the onset position in a word. English Phonotactics allow CC cluster and CCC clusters on the onset. In order to indigenize these clusters, Punjabi language insert vowels to convert them into CV or CVC configuration. It seems Punjabi insert mid central vowel /a/ as a default vowel in the CC configuration. The insertion of vowel can be between the consonants or before the consonants. The first type is called anaptyxis and the second type is called prothesis (Jabeen, 2012). In this section they will be dealt separately. The mid word vowel epenthesis in Punjabi is intended to make the cluster recognized on one hand and make it a simple syllable peak on the other hand. Breaking the $\mathrm{CC}$ consonant clusters mean the introduction of the new peaks to the $\mathrm{CC}$ cluster at the onset position. The epenthesis of vowel makes another syllable node among the existing nodes in the syllable. For the discussion of consonant clusters at the onset, researcher only discusses words with CC constructions on the onset position. It is described in the Figure 4.

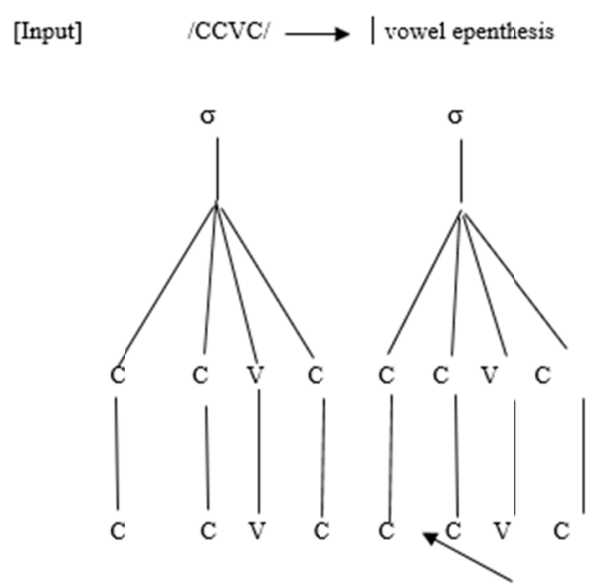

Monosyllabic construction
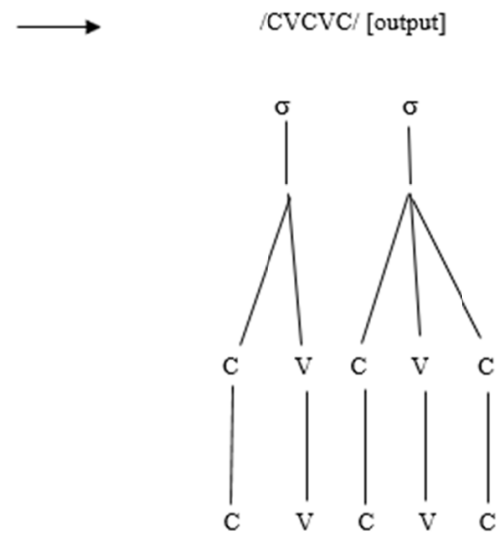

Polysyllabic construction

Figure 4. Insertion of vowel in consonant cluster 
It is evident in the Figure 4 that the epenthetic vowel creates a new node in the syllable. The monosyllabic word in CCVC configuration is converted into polysyllabic CVCVC configuration.

\subsubsection{Epenthesis of Mid Central Vowel/o/ in CC Clusters}

The Data for this study suggests that Punjabi speakers insert /o/ in a number of different consonant clusters in English loan words. This include the $\mathrm{s}+$ Stop, Stop + Liquids and Fricative + liquid Clusters. Due to homogeneity of data only representative example from each cluster is discussed. Punjabi speakers use central vowel /a/ extensively as an epenthetic vowel for the resolution of unrecognized CC clusters in English. It involves varied types of consonant clusters both at onset and coda positions. This study is focused on the epenthesis of vowels at the onset clusters with CC configuration. The first set of clusters in this regard is $\mathrm{s}+\mathrm{stop} /$ liquid clusters. Punjabi language does not accept any clusters at onset position so it has to be modified according to Punjabi phonological constraints. This is done by inserting /a/ vowel between the consonant cluster. The environments where $/ \partial /$ is inserted are numerous. All these environments are dealt similarly by the Punjabi speakers. Punjabi speakers use mid central vowel / $/$ / in all the cases.

The first cluster type where / $/ \mathrm{a} /$ is inserted are unvoiced alveolar fricative /s/ environment. The epenthesis is done in the /s/ environment. This include /sk/, /st/,/sp/,/sm/, /sn/and /sl/. An example of CC cluster phenomenon can be seen in the word /sku:1/ 'school'. The initial/sk/ cluster is repaired by inserting /a/ vowel. The first cluster type where / $/ \mathrm{a}$ is inserted are unvoiced alveolar fricative /s/ environment. The epenthesis is done in the $\mathrm{s}+\mathrm{stop}$ environment. This include /sk/, /st/, /sp/, /sm/, /sn/and/sl/. An example of CC cluster phenomenon can be seen in the word /sku:1/ 'school'. The initial/sk/ cluster is repaired by inserting /a/ vowel.

\subsubsection{Insertion of /a/ in /sk/ Cluster.}

The first cluster type in discussion is /sk/ cluster. The /sk/ consonant cluster type does not exist in Punjabi language. Thus, the Punjabi speakers do not recognize this environment. The examples of this type of cluster is /sku:1/ 'school', Punjabi speaker insert mid central vowel /a/in the cluster. The insertion of /a/ is discussed in Figure 4.

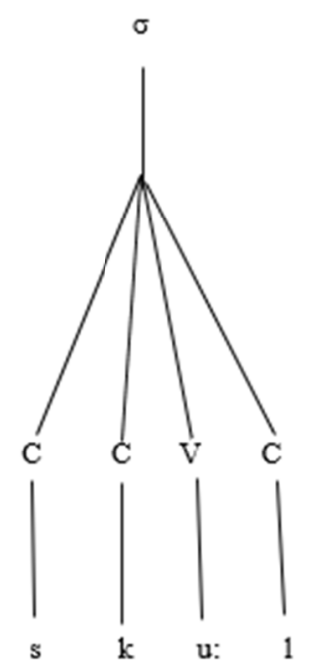

Figure 5. Syllable structure of the /sku:1/ 'school'

In the example given in Figure 5 the words /sku:1/ 'school' presents Punjabi speaker a different situation in terms of phonotactic constraint applied by Punjabi Phonology. The words school consist of a syllable with CCVC configuration. Punjabi Language does not accept this cluster. In order to deal with this situation Punjabi speaker has two options: either to break the CCVC configuration into CV.CVC by inserting a vowel into the cluster or make it a VC.CVC structure by inserting a vowel before the first consonants. In both the cases the monosyllabic word /sku:1/ will be broken down into disyllabic word. This is shown in the Figure 6. 


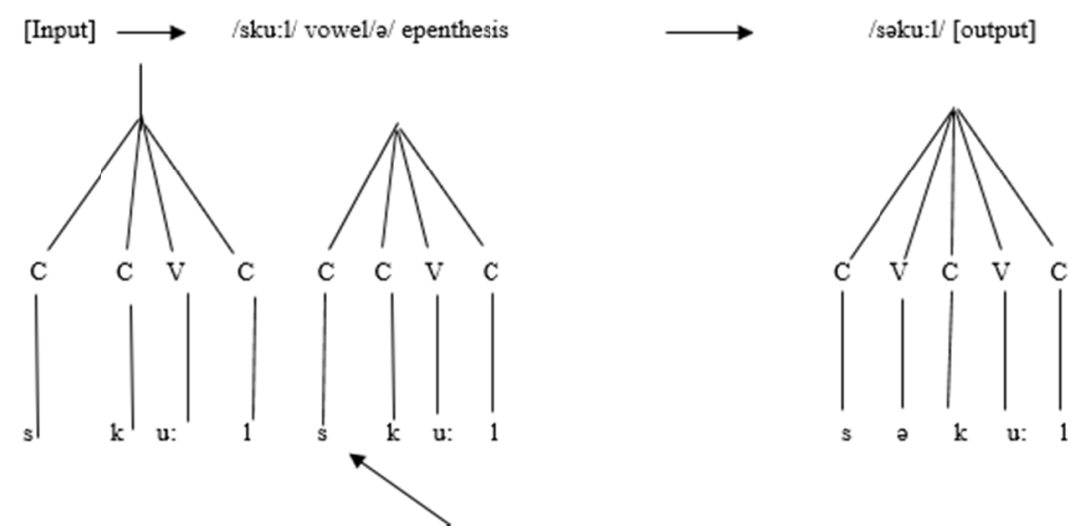

Figure 6. Insertion of vowel /a/ in /sk/ structure

The insertion of central vowel /a/ enables the Punjab speakers to convert unrecognized CC structure into a recognized CVC structure and thus, permits a speaker to pronounce it according to Punjabi phonotactic constraints. This insertion is also in line with the sonority sequence principle. The extra syllabic/s/ sound in English is converted into an initial consonant following the sonority hierarchy. It also enables the speakers to modify it according to the syllable length acceptable in Punjabi phonology. It is an example of cluster medial insertion or anaptyxis. The insertion of the vowel creates new node thus, the monosyllabic configuration will be converted into polysyllabic construction. This is shown in Figure 7 where the word /skert/ 'skate' is discussed.
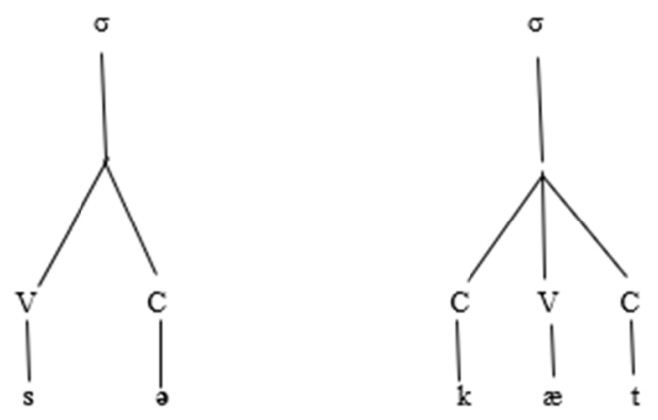

Monosyllabic construction

polysyllabic construction

Figure 7. Change of monosyllabic /skert/ 'skate' into polysyllabic construction

\subsubsection{Insertion of Vowel /e/ before the CC Consonant Cluster.}

In the previous section the insertion of the vowel in the s+ stop type of consonant cluster is discussed. The procedure adopted by the Punjabi speakers to deal with this kind of situation is to insert mid central vowel /o/ in $\mathrm{CC}$ configuration at the onset thus, converting it into CVC configuration. In addition to it, Punjabi speakers use another strategy to deal with undesired s+stop type of configuration. Punjabi speakers insert /e/ vowel at the initial position of the syllable before the consonant clusters only in s+stop clusters. This insertion of vowel at the initial position on one hand resolve the undesired consonant cluster at the onset position and on the other hand it breaks the branching onset and convert a monosyllabic construction into disyllabic construction. Hence, the CCVC configuration is converted into VC.CVC configuration. In case of s+liquide clusters where insertion of /a/ in the cluster is done exactly the same way insertion of /e/ before the cluster is not acceptable. The $\mathrm{s}+\mathrm{stop}$ clusters: /sp/, /sk/, /st/, sm/and /sn/ are converted to $\mathrm{e}^{+} \mathrm{s}+$ stop configurations. This is shown in the Figure 8 . 


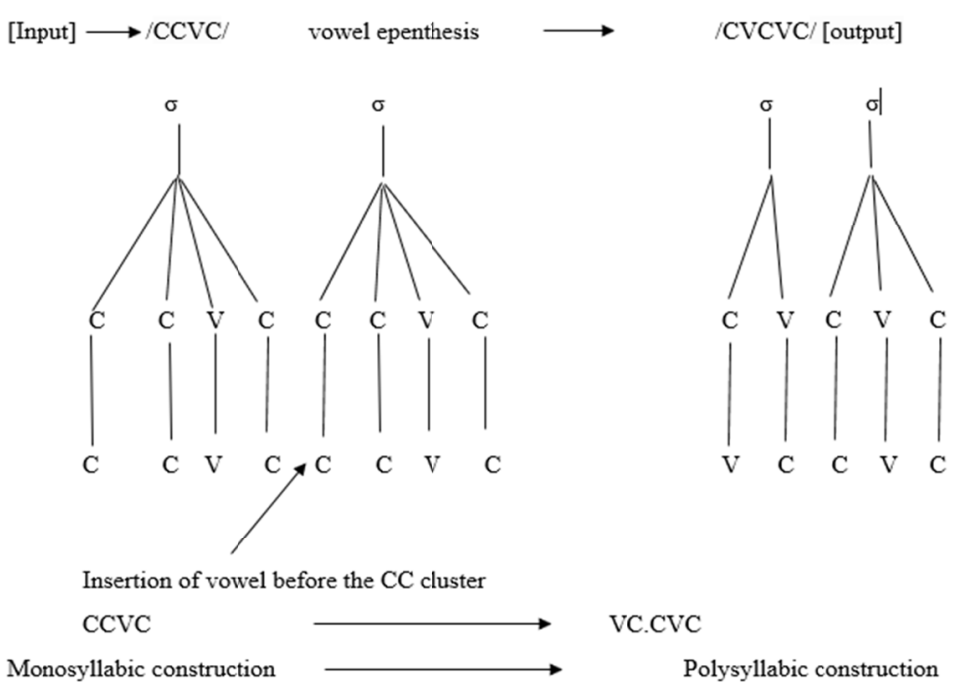

Figure 8. Insertion of mid-front vowel /e/ before the onset

The insertion of mid front vowel /e/ before the onset consonant cluster in the word /spr: $\mathrm{d} /$ 'speed' is illustrated in Figure 9.

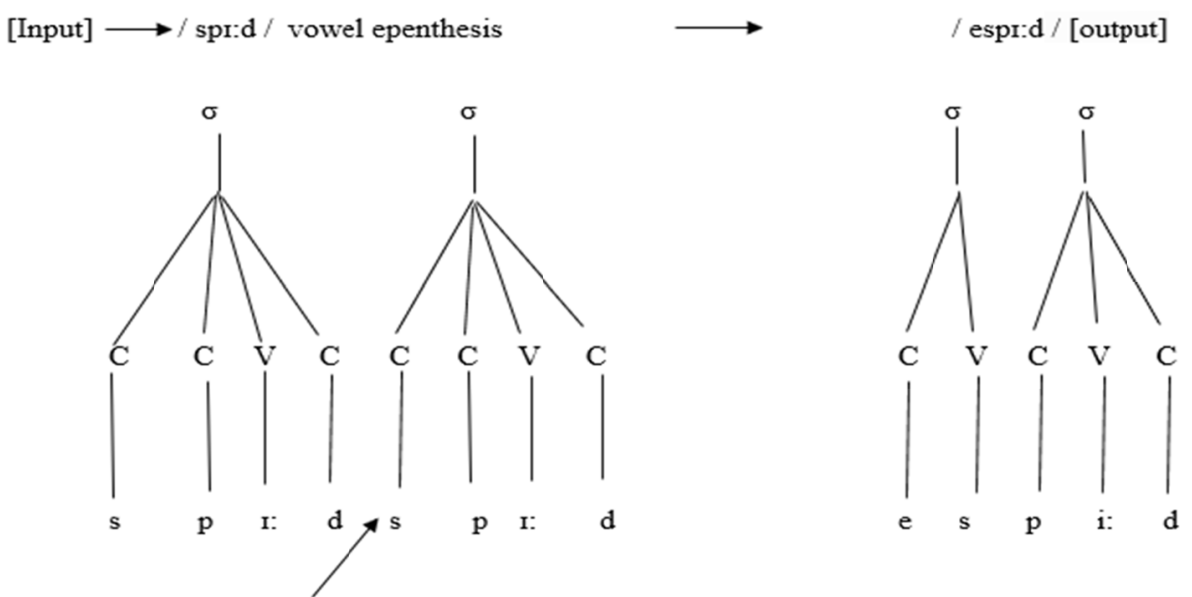

Figure 9. Insertion of vowel /e/ before the /sp/ cluster

With the insertion of vowel /e/ the monosyllabic CCVC configuration is converted in to polysyllabic VC.CVC construction. This configuration is acceptable in Punjabi Phonology. All the other cluster types are given in Table 1.

Table 1. The epenthesis of the vowel/a/ and /e/

\begin{tabular}{lllll}
\hline Cluster Type & Gloss & English transcription & $\begin{array}{l}\text { Punjabi transcription } \\
\text { (anaptyxis) }\end{array}$ & $\begin{array}{l}\text { Punjabi transcription } \\
\text { (prothesis) }\end{array}$ \\
\hline$/ \mathrm{sk} /$ & School, & sku:1 & səku:l & esku:l \\
$/ \mathrm{st} /$ & Stool & stu:1 & sətu:1 & estu:1 \\
$/ \mathrm{sp} /$ & Speed & spi:d & səpı:d & espr:d \\
$/ \mathrm{sm} /$ & Smoke & smo:k & səmo:k & esmo:k \\
$/ \mathrm{sn} /$ & Snail & sneil & səneil & esneil \\
$/ \mathrm{sl} /$ & Slip & slip & səlip & eəlip \\
\hline
\end{tabular}




\subsubsection{Insertion of /a/ in Stop + Liquids and Fricative + Liquid Clusters}

In this section, the Insertion of /a/ in Stop + Liquids and Fricative + Liquid is discussed. Punjabi speakers insert $/ \mathrm{a} /$ in both types of clusters in same way as it is inserted in the $\mathrm{s}+$ stop cluster. Here again the vowels are inserted between the CC consonant cluster at the onset of the syllable. In doing so, Punjabi changes the CCVC configuration into more discernable CV.CVC structures. Stop + Liquid cluster include /pr/, /tr/, /br/, /kr/, /bl/, $/ \mathrm{pl} /$ and $/ \mathrm{kl} /$ clusters and Fricative + Liquid clusters include /fl/and /fr/ clusters. Both types of clusters are dealt much in the similar way to the $\mathrm{s}+$ Stop clusters. Thus, only representative example is taken for this study. The process of epenthesis of central vowel /ə/ in the word /preiz/ 'praise' can be seen in the Figure 10.

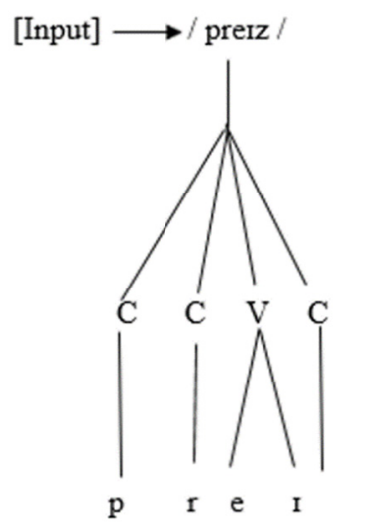

vowel/2/ epenthesis
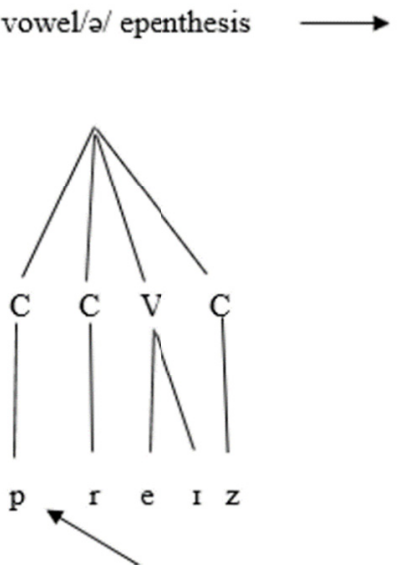

/ pareiz/ [output]

Figure 10. Insertion of /a/ in /preiz/

The insertion of /a/ in the CC cluster enables the Punjabi speakers to break the undesirable CC configuration into a recognizable configuration. On the other hand, this insertion breaks the monosyllabic configuration into polysyllabic constructions. The example of this construction is given in the Figure 11.
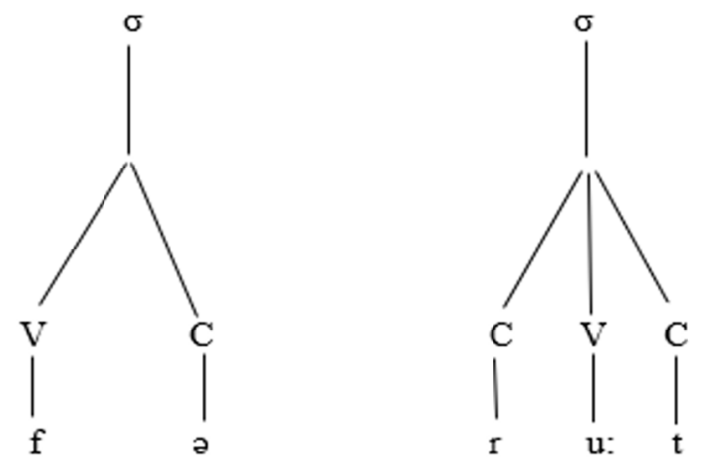

Monosyllabic construction

polysyllabic construction

Figure 11. Change of Monosyllabic /fru:t/ into polysyllabic /fəru:t/

Figure 11 shows the change of the syllable structure. The insertion of Vowel /a/ not only make the syllable structure according to Punjabi phonological constraints but also break the monosyllabic configuration into polysyllabic construction. The only difference is that Punjabi speakers insert / a/ in the CC in Stop + Liquid and Fricative + Liquid clusters but not before the cluster. The examples of both cluster types are given in the table 2 and 3. 
Table 2. Insertion of /a/ in stop + liquids

\begin{tabular}{llll}
\hline Cluster Type & Gloss & English transcription & Punjabi transcription (anaptyxis) \\
\hline$/ \mathrm{pr} /$ & pray & preI & pəreI \\
$/ \mathrm{tr} /$ & tray & treI & tore \\
$/ \mathrm{br} /$ & broom & bru:m & bəru:m \\
$/ \mathrm{kr} /$ & crack & krak & kərak \\
$/ \mathrm{bl} /$ & bloom & blu:m & bəlu:m \\
$/ \mathrm{pl} /$ & plate & pleit & pəle:t \\
$/ \mathrm{kl}$ & clear & kleə & kəleə \\
\hline
\end{tabular}

Table 3. Fricative + liquid clusters /fl/and /fr/

\begin{tabular}{llll}
\hline Cluster Type & Gloss & English transcription & Punjabi transcription (anaptyxis) \\
\hline$/ \mathrm{fl} /$ & flood & flıd & fəlıd \\
$/ \mathrm{fr} /$ & free & fri: & fəri: \\
\hline
\end{tabular}

\subsubsection{Epenthesis of Mid Central Vowel/ə/ in CCC Clusters}

Punjabi does not have a consonant cluster at the onset position in a syllable. On the other hand, English possesses consonant clusters at the onset position in a word. English phonology allows both CC cluster and CCC clusters on the onset. This section provides the epenthesis of vowel in consonant cluster of CCC configuration. In the CCC configuration the vowel is inserted between the consonants. In order to indigenize these clusters, Punjabi language insert vowels to convert them into CVCVC. The mid word vowel epenthesis in Punjabi is intended to make the cluster recognized on one hand and make it a simple syllable peak on the other hand. Breaking the CCC consonant clusters mean the introduction of the new peaks to the CCC cluster at the onset position. Thus, the epenthesis of vowels introduces new syllable nodes among the existing nodes in the syllable. For the discussion of consonant clusters at the onset researcher only discusses words with CCC constructions on the onset only It is described in the Figure 12.

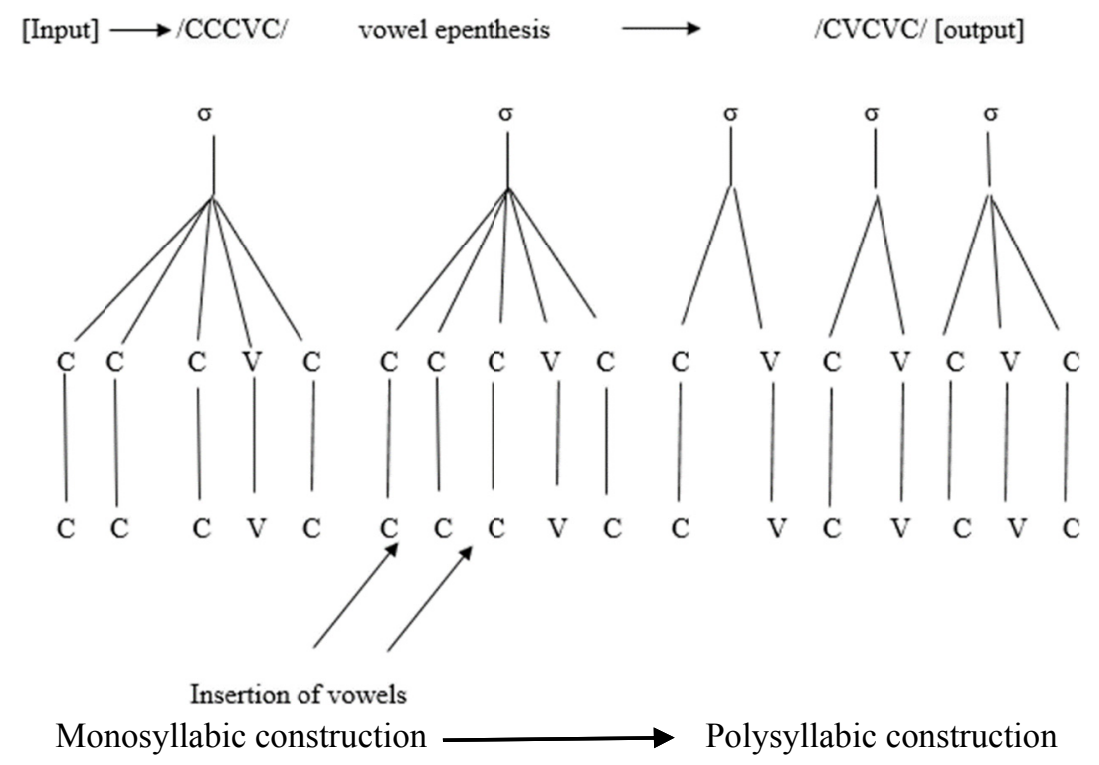

Figure 12. Insertion of vowel in CCC clusters

It is evident in the figure that the epenthetic vowels created new nodes in the syllable. The monosyllabic word in CCCVC configuration is converted into polysyllabic CV.CV. CVC configuration. Thus, converting single syllable into three syllables.

\subsubsection{Epenthesis of Mid Central Vowel/a/ in /spr/ Clusters}

The clusters containing CCC configuration at onset present Punjabi speakers a great deal of difficulty. The epenthesis of /a/ in CCC cluster is imposed by the fact that vowel /a/ should assimilate the preceding vowel, which in this case is /a/ in the syllable. For the resyllabification of words with /spr/ cluster at the onset the vowel 
$/ \mathrm{o} /$ is epenthesised preceding in $/ \mathrm{sp} /$ cluster and then in $/ \mathrm{pr} /$ clusters. It enables the Punjabi speaker to break the CCC construction into acceptable Punjabi clusters. The example of /spr/ clusters are /sprin/ 'spring', /spred/ 'spread', /sprint/ 'sprint' the epenthesis of mid central vowel /ə/ is shown in the Figure 13.

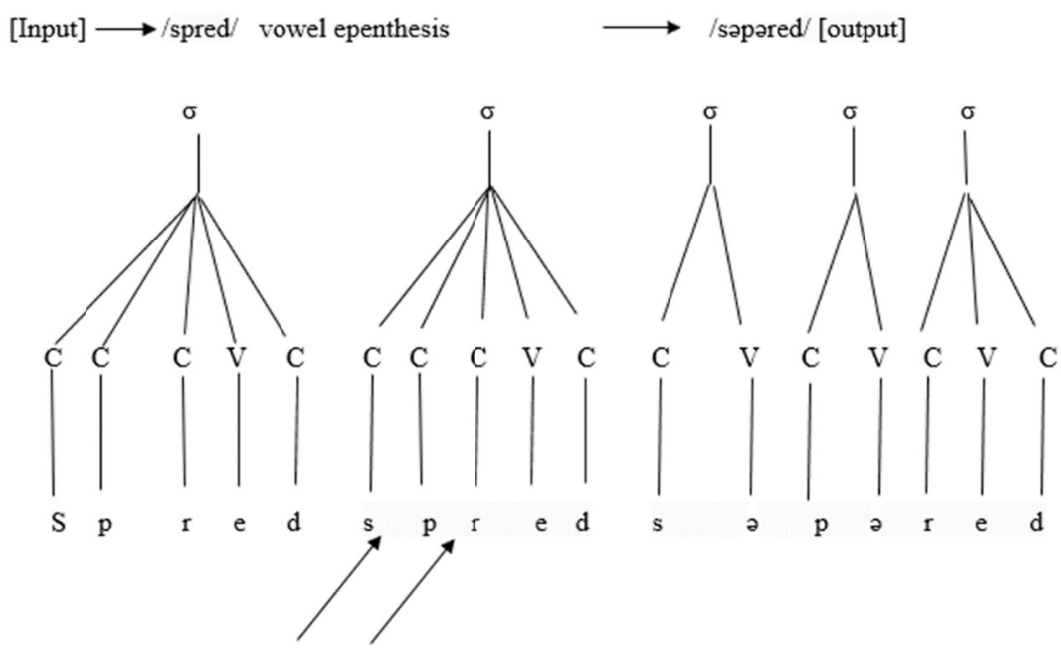

Insertion of vowel /a/

Figure 13. Epenthesis of mid central vowel/o/ in /spr/ clusters

The insertion of /a/ in the word /spred/ enables the Punjabi speakers to break the undesirable CCVC structure into a recognizable CV.CV.CVC structures. In addition to it, this epenthesis breaks the monosyllabic configuration into polysyllabic constructions. The example of this construction is given in the Figure 14.
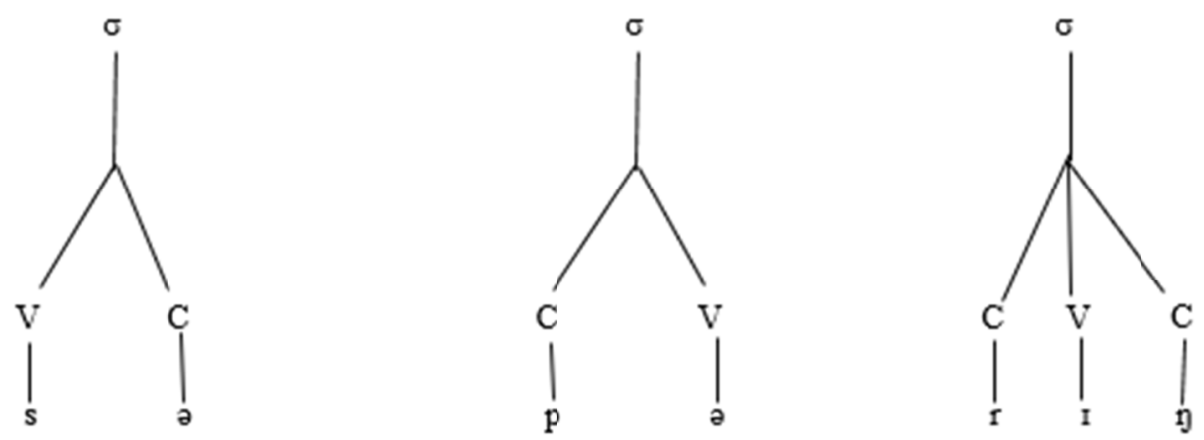

Monosyllabic construction

Polysyllabic construction

Figure 14. Change of monosyllabic /sprıy/ into polysyllabic /səpərın /

From the Figure 14, it is clear that the insertion of /a/ vowels in $/ \mathrm{sp} /$ and $/ \mathrm{pr} /$ created new nodes in the syllable. The monosyllabic word /sprin/ with CCCVC configuration is converted into /səpərin / with polysyllabic CV.CV. CVC configuration. Thus, converting single syllable into three syllables. All the clusters with CCCVC configuration are described in Table 4.

Table 4. CCCVC clusters

\begin{tabular}{llll}
\hline Cluster Type & Gloss & English transcription & Punjabi transcription \\
\hline$/$ spr/ & sprint & sprint & səpərınt \\
$/$ skr/ & scream & skrr:m & səkərr:m \\
$/$ str/ & strong & strny & sətəron \\
\hline
\end{tabular}




\section{Conclusion}

From the study, it is clear that all the clusters having CC or CCC configuration at onset of syllable are modified by inserting /o/ vowel as anaptyxis. Punjabi speakers use epenthesis to integrate English loan words with consonants at the onset cluster. /s/ as the first consonant are dealt with either the insertion of $/ \mathrm{a} /$ inside the cluster or the insertion of /e/ vowel before the consonant clusters. The process of insertion of vowel/a/ or /e/ is not arbitrary act but a systematic process. The epenthesis of mid front vowel /e/ not only help the Punjabi speaker to integrate the loan words with branching onset but it also breaks the monosyllabic complex CCVC structure in to polysyllabic VC.CVC structure.

The Insertion of vowel / $/$ / not only help the Punjabi speaker to integrate the loan words with branching onset but it also breaks the monosyllabic complex CCVC structure in to polysyllabic CVCVC structure. Here, it is important to note the process of epenthesis poses an interesting question: either the structure will be broken into CVC.VC configuration or CV.CVC. The plausible explanation is provided by the two principles namely Sonority sequence principle (SSP) and Maximal onset principle (MOP). English words with $/ \mathrm{s}+\mathrm{stop} /$ at the onset consider /s/ as an extra syllabic phoneme while Punjabi language does not allow /s/ as an extra syllabic consonant. Punjabi strictly follows the sonority sequences and hence it enables the English /s/ sound to become an initial consonant rather than extra syllabic consonant. The first principle is followed in either cases. Both CV.CVC and CVC.VC followed the SSP. The second principle MOP provides the answer. The Punjabi speakers prefer MOP hence, they prefer CV.CVC configuration. The auditory data taken for this study, confirmed that the Punjabi speakers will break the complex onset into simple structure in a way that the $/ \mathrm{a} /$ is assimilated with the first sound which in this case is /s/. The structure of the word /spr:d/ 'speed' after vowel insertion has become /sə.pr:d/. The structure thus, formed is given in the Figure 15.
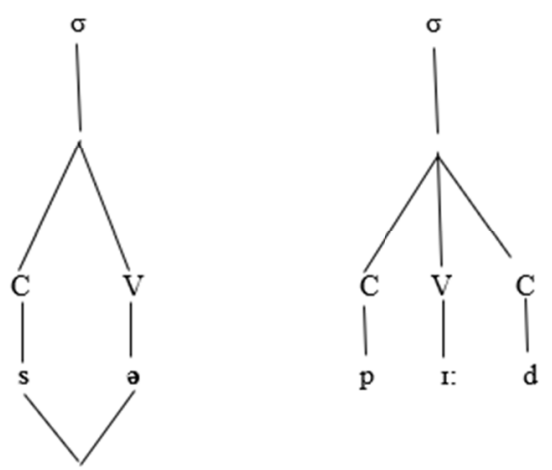

Figure 15. Onset vowel assimilation (OV) [+cont], [-round]

The feature assimilation of the vowel /a/ shows that the vowel $/ \mathrm{\partial} /$ is inclined towards voiceless fricative $/ \mathrm{s} / \mathrm{sound}$ rather than bilabial stop $/ \mathrm{p} /$. The sound $/ \mathrm{s} /$ is [+cont], [-round] and [+sibilant] while vowel $/ \mathrm{a} /$ is [-round], [+cont] and [+ son]. On the other hand, the phoneme $/ \mathrm{p} /$ is [- cont], [-sibilant]. Thus, the feature assimilation of $/ \mathrm{s} / \mathrm{and} / \mathrm{a} /$ is more plausible that the sound $/ \mathrm{p} /$. Punjabi speakers follow a similar mechanism for the epenthesis of vowel in other unrecognized clusters at onset position as mentioned above. The assimilation process thus, follow the same sequence as for the $\mathrm{s}+$ Stop clusters.

On contrast to the epenthesis of /a/ vowel where it was difficult to decide the structure of the syllables, the epenthesis of vowel /e/ gives a clear VC.CVC syllable structure. With the insertion of vowel /e/ the loan word with an extra syllabic/s/ sound is converted into simple structure following both Sonority sequence principle (SSP) and Maximal onset principle (MOP). The auditory data taken for this study, confirmed that the Punjabi speakers will break the complex onset into simple structure in a way that the /e/ is assimilated with the first sound which in this case is $/ \mathrm{s} /$. The structure of the word /spr:d/ 'speed' after vowel insertion has become /es.pr:d/. The structure thus, formed is given in the Figure 16. 


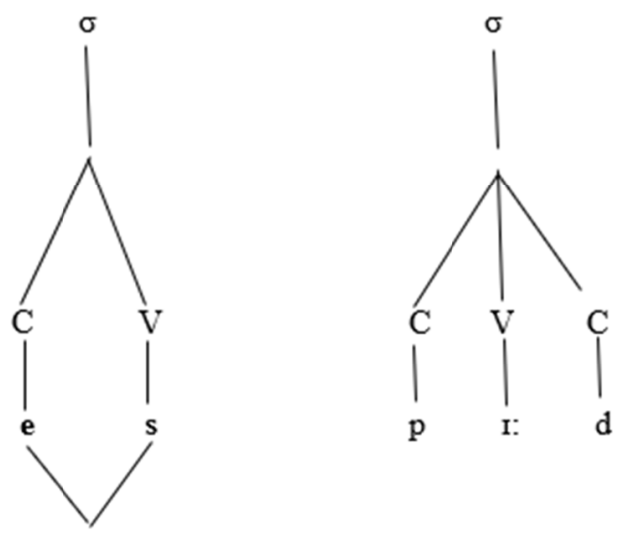

Figure 16. Feature assimilation (VO) [+cont], [-round]

In the similar way, the monosyllabic words with CCCVC configuration is converted into polysyllabic CV.CV. CVC configuration. Thus, converting single syllable into three syllables. This also involves the closed English syllable to two open syllables and a closed syllable. The epenthesis of mid central vowel /a/ is done with the harmony of vowels which is /ə. ə/. This harmony is described if Figure 17.
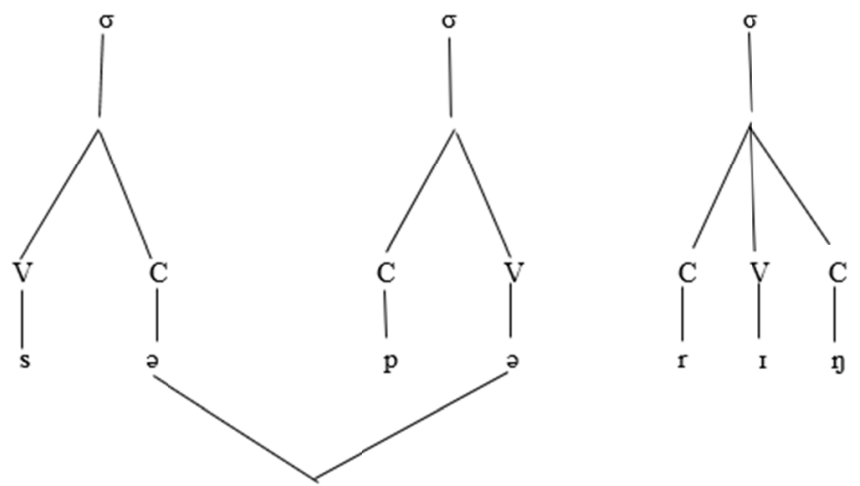

Figure 17./ə/ harmony

The insertion of /a/ is not random but necessitated by the harmonizing vowels in the adjoining syllable. The epenthesis of $/ \mathrm{a} /$ is done in the onset consonant cluster of Punjabi syllables to modify the illicit sequence of consonants and vowels that are not recognized in Punjabi phonology. The important question is to know which vowel can be assorted for the process of epenthesis. There are different reasons for the selection of the epenthesis of vowel, According to Uffmann (2012) For the determination of vowel quality, three different procedures are generally followed across languages. The first procedure followed is the insertion of default vowel. It entails that there is a vowel consistently inserted in different situations. The second reason for the determination of epenthetic vowel quality is the insertion of vowel of the quality of adjacent vowel. It is generally known as copy vowel or vowel harmony. The third reason is the effect of the quality of preceding consonant on the vowel. This phenomenon is called consonant assimilation. For the insertion of /a/ Punjabi, followed the first procedure mentioned by (Uffmann, 2012). According to the data selected for this study, the central vowel /a/ is found to be the default epenthetic vowel mainly inserted in initial consonant cluster in Punjabi Language. The last two procedures are not used by the Punjabi speakers to amend the clusters.

\section{References}

Baart, J. L., \& Baart-Bremer, E. L. (2001). Bibliography of Languages of Northern Pakistan: National Institute of Pakistan Studies. Quaid-i-Azam University Islamabad.

Bloomfield, L. (1933). Language, Holt, Rinehart and Winston. New York. Google Scholar.

Clements, G. N., \& Keyser, S. J. (1983). Cv phonology. a generative theory of the syllabe. Linguistic Inquiry Monographs Cambridge. Mass, 9, 1-191. 
Comrie, B., Matthews, S., \& Polinsky, M. (1996). The atlas of languages: The origin and development of languages throughout the world. Facts on file New York.

Crystal, D. (1997). A Dictionary of Linguisticsand Phonetics. London: Blackwell PublishersLtd.

Fromkin, V., \& Rodman, R. (1998). An Introduction to Language (6th ed.). Orlando: Harcourt Brace Collage Publisher.

Hall, N. (2011). Vowel epenthesis. The Blackwell Companion to Phonology, 1-21. https://doi.org/10.1002/9781444335262.wbctp0067

Hock, H. H. (2003). Analogical change. The Handbook of Historical Linguistics, 441-460. https://doi.org/10.1002/9780470756393.ch11

Jabeen, F., Muhmood. M. A., \& Asgher. M. (2012). Vowel Epenthesis in Pakistani English. Interdisciplinary Journal of Contemporary Research in Business, 3(10), 224-233.

Jakobson, R. (1971). Selected Writings (Ed. Stephen Rudy, six volumes)(Volume I. Phonological Studies). The Hague, Paris: Mouton.

Kadenge, M. (2003). The influence of Shona phonology on the English speech of first language (L1) Shona speakers of English: With specific reference to vowels. Unpublished Honours Dissertation.

Ladefoged, P., \& Johnson, K. (2014). A course in phonetics. Nelson Education.

Laver, J. (1994). Principles of phonetics. Cambridge Textbooks in Linguistics, 48, 51. https://doi.org/10.1017/CBO9781139166621

Muller, F. M. (1871). Lectures on the Science of Language (2 vols). London: Longmans, Green and Company.

Myers-Scotton, C. (2005). Multiple voices: An introduction to bilingualism. Wiley-Blackwell.

Poplack, S., \& Levey, S. (2010). Contact-induced grammatical change: A cautionary tale. Language and Space: An International Handbook of Linguistic Variation, 1, 391-419. https://doi.org/10.1515/9783110220278.391

Rahman, T. (1999). Language, education, and culture. Oxford University Press Karachi.

Rahman, T. (2002). Language, ideology and power: Language learning among the Muslims of Pakistan and North India. Oxford University Press Karachi.

Rodgers, J. (1995). Using diachronic linguistics in the language classroom. The Modern Language Journal, III(2), 212-222. https://doi.org/10.1111/j.1540-4781.1995.tb05432.x

Thomason, S. G. (2003). Contact as a source of language change. The Handbook of Historical Linguistics, 687712. https://doi.org/10.1002/9780470756393.ch23

Thomason, S. G., \& Kaufman, T. (2001). Language contact. Citeseer. https://doi.org/10.1016/B0-08-043076-7/03032-1

Thomason, S. G., \& Kaufman, T. (2008). Language contact, creolization, and genetic linguistics. Univ of California Press.

Uffmann, C. (2012). Vowel epenthesis in loanword adaptation (Vol. 510). Walter de Gruyter. https://doi.org/10.1093/oxfordhb/9780199232819.013.019

Weinreich, U. (1953). Languages in contact. Findings and problems. Publications of the Linguistic Circle of New York, 1.

Zivenge, W. (2009). Phonological and morphological nativisation of english loans in Tonga. University of South Africa.

\section{Copyrights}

Copyright for this article is retained by the author, with first publication rights granted to the journal.

This is an open-access article distributed under the terms and conditions of the Creative Commons Attribution license (http://creativecommons.org/licenses/by/4.0/). 